\title{
THE
}

\section{A Test of the Parsons-Veronis Hypothesis on the Separation of the Gulf Stream}

\author{
Avijit Gangopadhyay \\ P. C. Cornillon \\ University of Rhode Island, pcornillon@uri.edu \\ D. Randolph Watts \\ University of Rhode Island, randywatts@uri.edu
}

Follow this and additional works at: https://digitalcommons.uri.edu/gsofacpubs

\section{Citation/Publisher Attribution}

Gaogopadhyay, A., Cornillon, P., \& Watts, D. R. (1990). A Test of the Parsons-Veronis Hypothesis on the Separation of the Gulf Stream. J. Phys. Oceanogr., 22(11), 1286-1301. doi: 10.1175/ 1520-0485(1992)0222.0.C0;2

Available at: https://doi.org/10.1175/1520-0485(1992)022<1286:ATOTPH>2.0.C0;2

This Article is brought to you for free and open access by the Graduate School of Oceanography at DigitalCommons@URI. It has been accepted for inclusion in Graduate School of Oceanography Faculty Publications by an authorized administrator of DigitalCommons@URI. For more information, please contact digitalcommons-group@uri.edu. 


\title{
A Test of the Parsons-Veronis Hypothesis on the Separation of the Gulf Stream
}

\author{
Avijit Gangopadhyay, ${ }^{*}$ Peter CoRnillon, and D. Randolph Watts \\ Graduate School of Oceanography, University of Rhode Island, Narragansett, Rhode Island
}

(Manuscript received 10 May 1990, in final form 18 February 1992)

\begin{abstract}
The Parsons-Veronis model, based on a two-layer wind-driven ocean, predicts the latitude at which the western boundary current separates from the western boundary. It has been tested on the Gulf Stream using both satellite and in situ observations. The hypothesis attributes the difference in the thermocline depth from the eastern to the western side of the ocean and the corresponding northward geostrophic transport (with closed northern end) to the southward Ekman transport integrated across the basin. Twelve years (1977-88) of satellite sea surface temperature data and wind data [ from the Fleet Numerical Oceanography Center (FNOC) wind database ] have been used for this study. The satellite-derived Gulf Stream northern edges were used to determine the latitudes of separation (i.e., crossing the $2000-\mathrm{m}$ isobath into deep water).

Parsons" model is sensitive to two "free" parameters, namely, the reduced gravity and the thermocline depth on the eastern side of the basin. Based on available CTD data and previous current meter studies, these free parameters are selected to establish a representative two-layer model for the midlatitude North Atlantic. When the Ekman drift is integrated over several years, the predicted separation latitude variability agrees with observations with unit slope within $95 \%$ confidence limits. The relevant time scale of integration is on the order of 3 years, somewhat less than the estimated time for long baroclinic planetary waves to cross the Atlantic. For this limited dataset, little improvement in the prediction is found for a larger number of years of averaging. More detailed and long-term investigation of this hypothesis should be made in future in context of other western boundary currents.
\end{abstract}

\section{Introduction}

Despite recent developments in both analytical (Luyten et al. 1983) and numerical (Rhines and Young 1982) modeling of the ocean circulation, a particular difficulty still remains in identifying the separation mechanism for western boundary currents from the continental margin. There are two more or less independent approaches to this problem. An elegant description of these is provided by Pedlosky (1987). Briefly, the first, called separation by detachment, suggests that detachment of the northward-flowing geostrophic western boundary current in a two-layer ocean occurs at the latitude at which the interface between the two layers intersects the surface. This was first shown by Parsons (1969) in a simple two-layer winddriven model ocean, in which the path of the western boundary current is deduced by relatively simple considerations of mass balance and geostrophy. This approach was later extended by Veronis (1973) and by Huang and Flierl (1987) to deal with basins containing both subtropical and subpolar gyres.

\footnotetext{
* Present affiliation: Center for Earth and Planetary Sciences, Harvard University

Corresponding author address: Dr. Avijit Gangopadhyay, Harvard University, Department of Earth and Planetary Sciences, Pierce Hall, Cambridge, MA 02138.
}

The second approach, called the potential vorticity crisis mechanism, was first put forward by Greenspan (1962). In this approach, the criterion for the existence of an inertial boundary layer is governed by the sign of the potential vorticity gradient in the direction of the outward normal to the boundary. Greenspan noted that both the Gulf Stream and Kuroshio separate from the coast where the coastline changes curvature, thereby justifying this criterion. In this paper, we do not explore this hypothesis.

It is the purpose of this study to investigate the validity of the separation hypothesis introduced by Parsons (1969) and extended by Veronis (1973). We begin with a detailed exposition of the Parsons-Veronis hypothesis in section 2 . This is followed by a discussion of the datasets used for this study. Section 4 deals with the establishment of a two-layer model of the North Atlantic at approximately $35^{\circ} \mathrm{N}$ and the selection of the free parameters for this model. The findings of this work and how they relate to the broader perspective of the Gulf Stream system and the wind-driven basinwide circulation are discussed in section 5 .

\section{Parsons-Veronis hypothesis}

a. The model

Consider a two-layer ocean (Fig. 1), with the lower layer at rest, forced by a steady zonal wind stress $(\tau)$. 


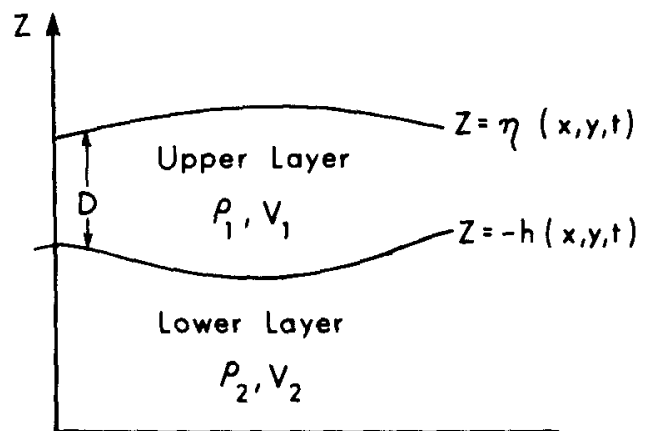

Fig. 1. The notation used to describe the two-layer model ocean. The $z$ axis points vertically upward, $z=\eta(x, y, t)$ is the surface elevation; $z=-h(x, y, t)$ is the position of the interface between the two layers; and $D=\eta+h$ is the depth of the upper layer.

The $x$-component horizontal momentum equation for each layer is

$$
\begin{aligned}
& -f v_{1}=-g \frac{\partial \eta}{\partial x}+\frac{\tau}{\rho_{1} D} \\
& -f v_{2}=-\frac{\rho_{1}}{\rho_{2}} g \frac{\partial \eta}{\partial x}+g^{\prime} \frac{\partial h}{\partial x},
\end{aligned}
$$

where $\rho_{1}, v_{1}$ and $\rho_{2}, v_{2}$ are the densities and velocities of the upper and lower layers, respectively; $\eta$ is the free surface variation; $h$ is the depth of the interface; and $g^{\prime}=g\left(\rho_{2}-\rho_{1}\right) / \rho_{2}$. The upper layer thickness $D=\eta$ $+h$ is the sum of the free surface variation $\eta$ plus the interface depth variation $h$. Thus,

$$
\frac{\partial D}{\partial x}=\frac{\partial \eta}{\partial x}+\frac{\partial h}{\partial x} \text {. }
$$

Assuming the lower layer is at rest, $v_{2}=0$ in conjunction with (2) and (3) yields

$$
\frac{\partial D}{\partial x}=\frac{\rho_{2}}{\rho_{2}-\rho_{1}} \frac{\partial \eta}{\partial x} \text {. }
$$

Substituting (4) into ( 1 ) gives

$$
-f v_{1}=-g^{\prime} \frac{\partial D}{\partial x}+\frac{\tau}{\rho_{1} D} \text {. }
$$

Finally, multiplying (5) by $D / f$ and integrating along $x$ from the western to the eastern boundary yields

$$
\int_{x_{\mathrm{W}}}^{x_{\mathrm{E}}} v_{1} D d x=\frac{g^{\prime}}{f} \int_{x_{\mathrm{W}}}^{x_{\mathrm{E}}} \frac{\partial D}{\partial x} D d x-\int_{x_{\mathrm{W}}}^{x_{\mathrm{E}}} \frac{\tau}{\rho_{1} f} d x
$$

which on simplification may be written as

$$
T_{1}=\frac{g^{\prime}}{2 f}\left(h_{\mathrm{e}}^{2}-h_{\mathrm{w}}^{2}\right)-T_{\mathrm{E}},
$$

where $h_{\mathrm{e}}$ and $h_{\mathrm{w}}$ are the depths of the interfaces at the eastern and the western boundary, respectively; $T_{1}$ is the first integral in (6) and is the total meridional transport across the basin at a given latitude; and $T_{\mathrm{E}}$ is the last integral in (6), which represents the Ekman drift. Note that the surface elevations at both the eastern and the western ends have been neglected in the above derivation because they are much smaller than the depths of the interface.

At the latitude of separation, since the thermocline surfaces, $h_{\mathrm{w}}=0$, and (7) becomes

$$
T_{1}=\frac{g^{\prime} h_{\mathrm{e}}^{2}}{2 f}-T_{\mathrm{E}}
$$

This equation states that the difference between the geostrophic transport and the Ekman drift at the separation latitude is given by a net northward transport into the northern end of the basin, that is, fluid lost out of the upper layer. This balance is illustrated in Fig. 2. The first term on the right-hand side of $(8)$ is the geostrophic transport integrated across the ocean basin, denoted by $T_{\mathrm{g}}$.

The transport, even in the Gulf Stream, is geostrophic to a very good approximation [e.g., Johns et al. (1989) show $1 \%$ agreement ]; so (5) is valid across the entire basin. Therefore, if the basin is closed to the north of the latitude of separation, $T_{1}$ must vanish in the steady state, and from (7), the depth of the interface at the western boundary is governed by the relation

$$
\frac{g^{\prime}}{2 f} h_{\mathrm{w}}^{2}=\frac{g^{\prime}}{2 f} h_{\mathrm{e}}^{2}-T_{\mathrm{E}}
$$

From (9) it follows that, for sufficiently large $T_{E}$, the right-hand side goes to zero; that is, the thermocline at the western boundary intersects the surface, $h_{\mathrm{w}}=0$. Typically $T_{E}$ increases to the north (Fig. 3) from $35^{\circ}$ to $40^{\circ} \mathrm{N}$. To maintain this balance, the western boundary current must therefore leave the continental margin

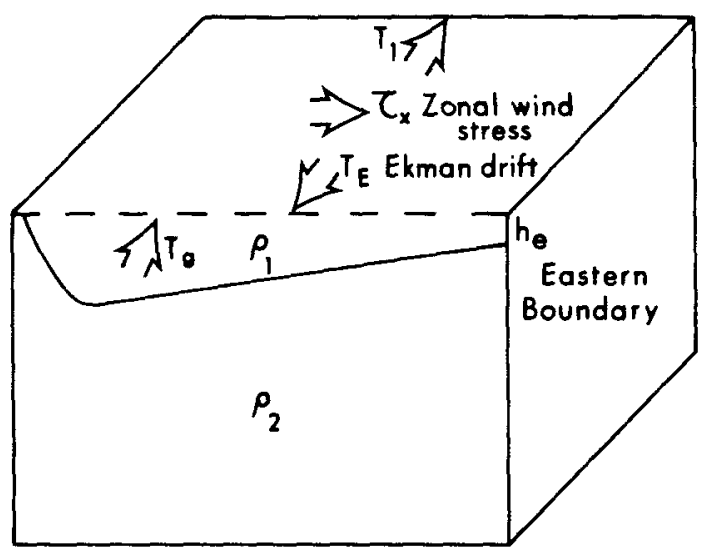

FiG. 2. The Parsons-Veronis Hypothesis shown above as a twolayer ocean from west to east. The densities are $\rho_{1}$ and $\rho_{2}$ for the upper and lower layers, respectively. The Ekman wind drift is shown as the southward transport $T_{\mathrm{E}}$; the net geostrophic transport to the north is shown as $T_{g}$; and the net northward transport at the northern boundary is denoted by $T_{1}$. The depth of the thermocline at the eastern end, $h_{e}$, is also indicated. 


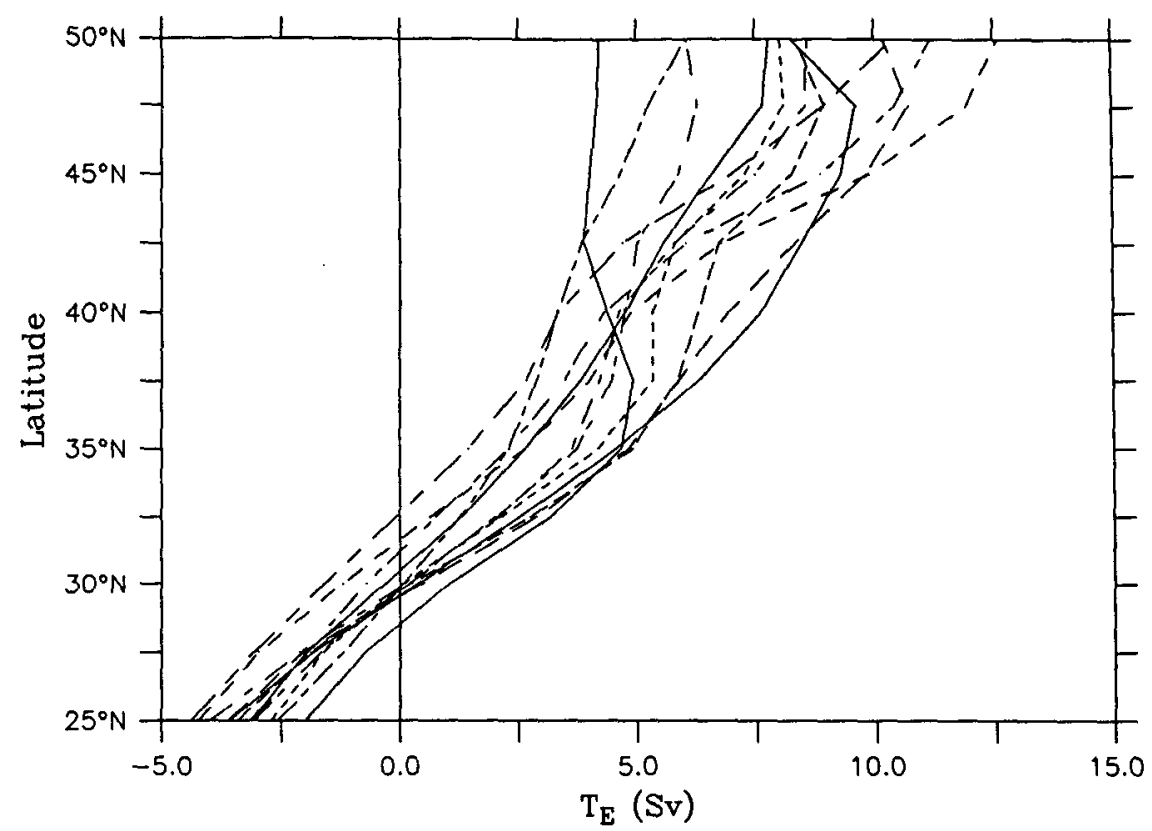

Fig. 3. Variation of the integrated zonal wind stress as represented by the annual mean Ekman wind drift with latitude. Different lines represent the 12 different years of data.

flowing to the northeast, thus reducing the Ekman drift integrated to the right of it. Thus, by evaluating both of the terms on the right-hand side of $(9)$, which requires knowledge of the latitudinal variation of $g^{\prime}, h_{\mathrm{e}}$ and of the integrated zonal wind stress across the basin, we are able to predict a separation latitude, the latitude at which these two terms cancel each other. Note that since the real ocean is open at the northern end and since thermohaline convection at high latitudes may exchange water from the upper to the lower layer, $T_{1}$ does not vanish in reality. We therefore expect a difference between the predicted and the observed point of separation. This difference can be attributed to a loss of fluid from the Gulf Stream system, which is discussed in section $5 \mathrm{e}$.

At the latitude of separation, substituting $h_{\mathrm{w}}=0$ in (9), the thermocline depth at the eastern boundary is given by $h_{\mathrm{e}}=\left(2 f T_{E} / g^{\prime}\right)^{1 / 2}$. In an average sense, the Ekman wind drift $T_{\mathrm{E}}$ can be represented by $\tau_{a v} L / \rho f$, where $\tau_{a v}$ is the mean zonal wind stress over the basin and $L$ is the width of the basin. Thus, the Parsons-
Veronis hypothesis would hold for basins for which the depth of the thermocline at the eastern boundary would be approximately given by $\left(2 \tau_{a v} L / \rho g^{\prime}\right)^{1 / 2}$. To test this we used climatological mean winds (Hellerman and Rosenstein 1983; Munk 1950) integrated across the North Atlantic, the South Atlantic, and the North Pacific at the latitudes at which the Gulf Stream $\left(35^{\circ} \mathrm{N}\right)$, Agulhas $\left(35^{\circ} \mathrm{S}\right)$, and Kuroshio $\left(35^{\circ} \mathrm{N}\right)$ leave the continental margin. For the North Atlantic basin,

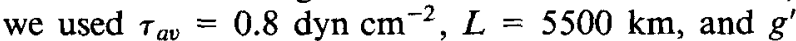
$=0.01 \mathrm{~m} \mathrm{~s}^{-2}$, from which $h_{\mathrm{e}}$ is predicted to be approximately $210 \mathrm{~m}$. For the South Atlantic $\tau_{a v}=0.4$ dyn $\mathrm{cm}^{-2}, L=5000 \mathrm{~km}$, and $g^{\prime}=0.01 \mathrm{~m} \mathrm{~s}^{-2}$ yield an $h_{\mathrm{e}}$ of $140 \mathrm{~m}$; and for the North Pacific with $\tau_{a v}=0.5$ dyn $\mathrm{cm}^{-2}, L=9000 \mathrm{~km}$, and $g^{\prime}=0.01 \mathrm{~m} \mathrm{~s}^{-2}, h_{\mathrm{e}}$ was found to be on the order of $290 \mathrm{~m}$. These different predicted thermocline depths agree well with observed climatological thermocline $\left(15^{\circ} \mathrm{C}\right.$ isotherm) depths as available from the Geosecs atlases (Craig et al. 1981) at the eastern boundaries of the respective basins ( Table 1). Note that the relative differences of the predicted

TABLE 1. Parsons-Veronis hypothesis parameters for different western boundary currents (WBCs).

\begin{tabular}{|c|c|c|c|c|c|c|}
\hline \multirow[b]{2}{*}{ Basin } & \multirow[b]{2}{*}{ WBC } & \multirow{2}{*}{$\begin{array}{l}\text { Separation } \\
\text { latitude }\end{array}$} & \multirow{2}{*}{$\begin{array}{c}\tau_{a v} \\
\left(\text { dyn } \mathrm{cm}^{-2}\right)\end{array}$} & \multirow{2}{*}{$\begin{array}{l}\text { Length } L \\
\quad(\mathrm{~km})\end{array}$} & \multicolumn{2}{|c|}{$h_{E}(\mathrm{~m})$} \\
\hline & & & & & Observed & $\tau_{a v} L / g^{\prime}$ \\
\hline North Atlantic & Gulf Stream & $35^{\circ} \mathrm{N}$ & 0.8 & 5500 & 250 & 210 \\
\hline North Pacific & Kuroshio & $35^{\circ} \mathrm{N}$ & 0.5 & 9000 & 300 & 290 \\
\hline South Atlantic & Agulhas & $35^{\circ} \mathrm{S}$ & 0.4 & 5000 & 150 & 140 \\
\hline
\end{tabular}

The values of $\tau_{a v}$ and the thermocline depth at the eastern boundary $\left(h_{E}\right)$ for different basins are climatological; $g^{\prime}=0.01 \mathrm{~m} \mathrm{~s}^{-2}$. 
upper-layer depths (a combined effect of average wind stress and the width of the basin) between different basins are consistent with corresponding climatological differences observed at the eastern boundaries. The rough agreement outlined above for the three major western boundary currents suggests a more detailed test of the hypothesis; a test in which the observed variability of the latitude of separation (in a long-term sense, temporal averages of 6 months and more) for a given western boundary current is considered as a function of similar averages of the basinwide wind stress. Such a study for the Gulf Stream is the focus of the remainder of this work.

\section{b. The response time period}

The response of a two-layer ocean to wind forcing has been studied in detail over the past three decades. Of importance here is the length of time following a step change in the wind for the oceanic circulation to reach a new steady-state configuration. Based on some heuristic arguments using energy conversion and the conservation of mass and by comparing the total volume of warm water mass against the surface convergence due to wind, Stommel (1962) suggested that the decay time period for complete cessation of the circulation after the wind forcing is removed is on the order of 1000-1700 days. Anderson et al. (1979) studied the transient response of the North Atlantic using a linearized version of Bryan's (1969) model. In studying the baroclinic adjustment processes using 1600day simulations, they noted that although the two-layer ocean does not attain complete equilibrium during this period, the main adjustments such as the steady-state velocities of the real ocean currents have already occurred by this time. These studies have shown that the response of the thermocline to the applied wind stress generates planetary waves propagating to the west and, on being reflected from the western boundary, forms the highly energetic western boundary current. It is now generally accepted that the steady-state response would be achieved after a time period consistent with the time taken by the baroclinic Rossby waves to cross the basin (Gill 1982). Anderson and Corry (1985) studied the linear low-frequency response of a two-layer ocean to periodic wind forcing and found that the steady-state boundary current is established for periods on the order of years to decades.

Since we have assumed a steady-state model [Eqs. (1) and (2)], but the winds available from the Fleet Numerical Oceanographic Center (FNOC) are instantaneous values changing every six hours, some form of temporal averaging is necessary to approximate the steady-state forcing. For the purpose of this study, these 6-hourly wind stress values are averaged over the basin for each year from 1977 to 1988 (Fig. 3). These annual averages are used to predict the separation latitude using (9). This is discussed in detail in section $5 \mathrm{a}$. We increased the averaging time for the Ekman transport in steps from 1 to 5 years and compared the predicted separation with the observed latitude at the end of each respective period. The agreement between the observation and the prediction improves as the time period of averaging is increased. This, we believe, is a reflection of the fact that the response time for a two-layer model is on the order of the time taken by the long Rossby waves to cross the Atlantic. The importance of the time scales of averaging in determining the predictions by the Parsons-Veronis hypothesis is discussed in detail in section $5 \mathrm{~d}$.

\section{Data analysis}

The path of the Gulf Stream has been determined from satellite infrared imagery for the period 1977-88. Weekly positions were obtained from the Experimental Ocean Frontal Analysis (EOFA) charts issued by NOAA for the period 1975-81. For the period 198288 , Gulf Stream paths were obtained every 2 days, cloud cover permitting, as part of a larger experiment by Cornillon et al. (1987). The satellite data used for the period 1979-88 were obtained from the Advanced Very High Resolution Radiometer (AVHRR) of the TIROS-N satellites (Schwalb 1978), while the data for the period 1977-79 were obtained from the Very High Resolution Radiometer carried on NOAA-S. Processing of the satellite data to locate the path of the Gulf Stream is described in detail by Gilman (1989). Approximately 1400 Gulf Stream paths were digitized for the period $1977-88$ in the region from $76^{\circ}$ to about $55^{\circ} \mathrm{W}$. These fronts have a resolution of $0.1^{\circ}$ longitude, that is, $11-\mathrm{km}$ spacing between successive digitized ordinates.

Annual averages of the separation point were constructed by first averaging the satellite-derived paths between $70^{\circ}$ and $75.5^{\circ} \mathrm{W}$ in annual intervals. This annual averaging was done to reduce the noise resulting both from the Gulf Stream meandering in the region (periods on the order of 30 days) and from the masking of surface anomalies. These paths, a portion of which are shown in Fig. 4a, were obtained by averaging the latitudinal value of all digitized paths at each $0.1^{\circ}$ of longitude. Also shown in Fig. 4a is the 2000-m isobath. The separation point is defined as the intersection of the annual average Gulf Stream path with the 2000-m isobath. The $2000-\mathrm{m}$ isobath was chosen because it is relatively smooth compared to, say, the $100-\mathrm{m}$ isobath and yet still represents well the edge of the continental shelf. Figure $4 \mathrm{~b}$ shows the latitude of the point of separation (solid line) as a function of time. Note that the latitudinal excursion of the separation position is on the order of $100 \mathrm{~km}$; whereas the longitudinal excursion (not shown) is only on the order of $30 \mathrm{~km}$. The smaller longitudinal excursion is due to the almost meridional orientation of the $2000-\mathrm{m}$ isobath.

The wind data used in this analysis are obtained 

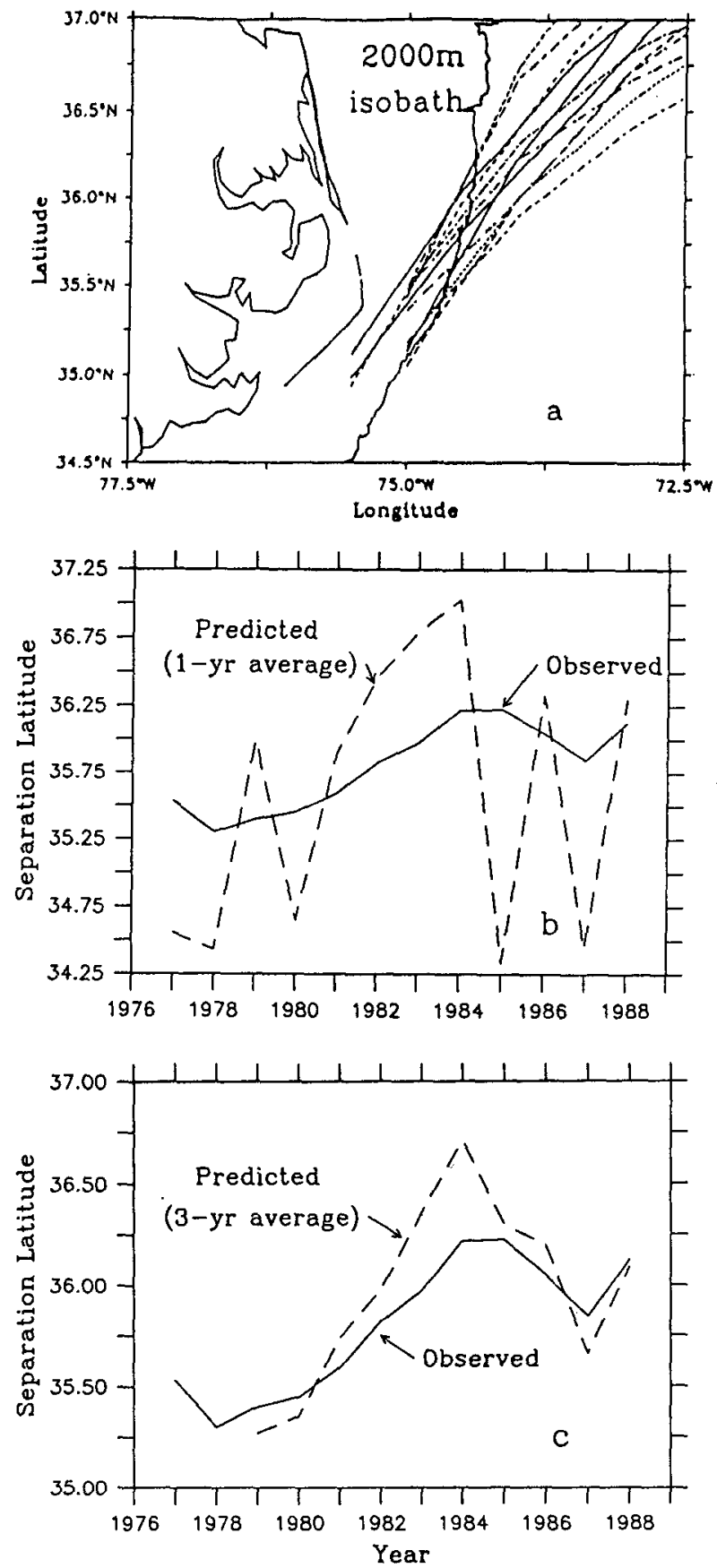

FIG. 4. (a) The annual mean Gulf Stream paths intersected by the 2000-m isobath for the 12-year (1977-88) study period. (b) The separation latitudes as observed from (a) plotted (solid line) as a 12year time series along with the annual prediction (dash line). (c) Similar to (b) with 3-year prediction time series.

from the Fleet Numerical Oceanographic Center (FNOC), Monterey, California. A detailed description of the model used to develop the FNOC winds can be found in Lewis and Grayson (1972). For this study, the northward and eastward components of the wind speed on a $2.5^{\circ}$ grid extending from the east coast of North America to $20^{\circ} \mathrm{W}$ and from $25^{\circ}$ to $50^{\circ} \mathrm{N}$ are used. The eastern limit for the wind data is chosen to be at $20^{\circ} \mathrm{W}$ to match the two-layer model's eastward extent, which is restricted by the intrusion of the Mediterranean salt tongue farther to the east. The zonal wind stress, $\tau_{x}$, at each grid point in this domain is evaluated at 6-hour intervals from the dataset using the bulk formula: $\tau_{x}=\frac{1}{2} \rho C_{d} u|\mathbf{u}|$, where $\rho$ is the air density, $C_{d}$ is the drag coefficient, $u$ and $v$ are the eastward and northward wind speeds, and $|\mathbf{u}|$ $=\sqrt{\left(u^{2}+v^{2}\right)}$. For this study, a stepwise drag coefficient of $C_{d}=0.0008$ for $|\mathbf{u}| \leqslant 6.6 \mathrm{~m} \mathrm{~s}^{-1}$ and $C_{d}$ $=0.0028$ for $|\mathbf{u}| \geqslant 6.6 \mathrm{~m} \mathrm{~s}^{-1}$ was used. More rigorous estimates of the drag coefficient do not seem to substantially improve the wind-stress estimates (Hsu 1986). The density of air is taken as $1.18 \mathrm{~kg} \mathrm{~m}^{-3}$. These 6-hourly zonal values are then averaged at every grid point over the analysis domain for one-year periods.

Finally, the $T_{\mathrm{E}}$ term of Eq. (9) is obtained by integrating the zonal wind stress on each of the horizontal grid lines from $25^{\circ}$ to $50^{\circ} \mathrm{N}$. The integration stops at the westernmost grid point nearest to the east coast of North America. The resulting values of $T_{\mathrm{E}}$ are plotted in Fig. 3 as a function of latitude for each of the 12 years used in this study.

\section{A two-layer model of the subtropical North Atlantic}

As discussed in section 2, separation of the Gulf Stream from the continental margin implies outcropping of the thermocline on the western side of the basin, with the line of outcropping extending to the north and east from the point of separation. This means that to the north and west of this line the water column in the Parsons-Veronis model ocean (hereafter referred to as slope water) consists of a single layer, while to the east and south of this line the model ocean consists of two layers. Therefore, for the two-layer model to accurately represent the real ocean, the depth of the density interface separating the two layers in the eastern portion of the study area must be chosen so that the characteristics of the water in the lower layer are representative of those of the entire water column in the slope water region on the western edge of the ocean. Once the density interface satisfying this condition has been defined, an estimate of the associated reduced gravity can be made from the depth-averaged densities of the upper and lower layers. In the following we discuss how CTD data, available from National Oceanographic Data Center (NODC), were used in conjunction with the ideas presented above to determine the appropriate density surface for the interface. At the end of this section, we show that the north-south slope of $h_{\mathrm{e}}$, a critical parameter in the problem discussed in section 5 , is consistent with observed geostrophic velocities in the eastern North Atlantic. 


\section{a. A consistent value of the reduced gravity for the North Atlantic at $35^{\circ} \mathrm{N}$}

To establish a representative two-layer model, vertical density profiles were obtained across the North Atlantic using all CTD casts available from the National Oceanographic Data Center (NODC) for the period $1977-86$. Five $10^{\circ}$ wide longitudinal regions were chosen for this purpose between $70^{\circ}$ and $20^{\circ} \mathrm{W}$ (Fig. 5). The north-south extent of these regions is from $30^{\circ}$ to $34^{\circ} \mathrm{N}$. A sixth region was chosen to represent the slope water. This region $\left(38^{\circ}-40^{\circ} \mathrm{N}, 74.5^{\circ}-\right.$ $72.5^{\circ} \mathrm{W}$ ), is also shown in Fig. 5, lying to the north of the mean path of the Gulf Stream for 1985 (Gilman 1989), a year in which the mean path was unusually far to the north. The criterion for selecting slope water CTD casts within this region, which were not in a Gulf Stream ring or in the stream itself, was that the $10^{\circ} \mathrm{C}$ isotherm be shallower than $350 \mathrm{~m}$ and was taken from Bisagni and Cornillon (1984). The number of available CTD casts in each of these regions is shown in Fig. 5. From each CTD cast a vertical profile of potential density was calculated using the International Equation of State of seawater (IES 80) (Millero and Poisson 1981). These profiles extend to depths of up to $2000-\mathrm{m}$ depth. To obtain a single profile for each of the boxes shown in Fig. 5, all density profiles falling within the given box were averaged. For the east-west analysis to be discussed first, all 36 casts lying between $30^{\circ}$ and $34^{\circ} \mathrm{N}$ are used for the $20^{\circ}$ to $30^{\circ} \mathrm{W}$ band. Two profiles, one for the box from $30^{\circ}$ to $32^{\circ} \mathrm{N}$, and a second for the box from $32^{\circ}$ to $34^{\circ} \mathrm{N}$, were obtained for the northsouth analysis to be discussed at the end of this section.

To determine $\bar{\rho}_{1}$ and $\bar{\rho}_{2}$ (see Fig. 2), the mean densities of the upper and the lower layers in the two-layer system from the vertical profiles of the potential density, these profiles are simply averaged from the surface

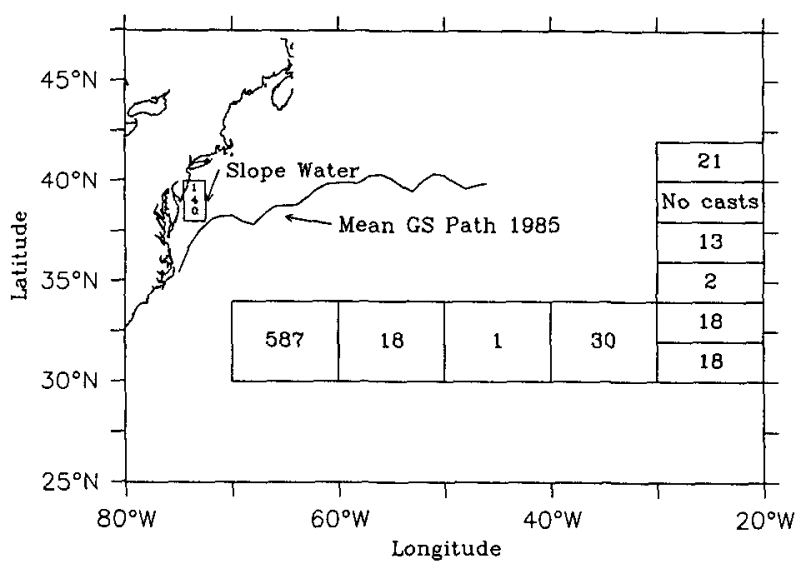

Fig. 5. The domain of analysis for this study. The North Atlantic basin is divided into a $2.5^{\circ} \times 2.5^{\circ}$ grid (not shown). The number of available CTD casts are indicated inside different regions of analysis. These casts are used to establish a two-layer representative model for the North Atlantic.

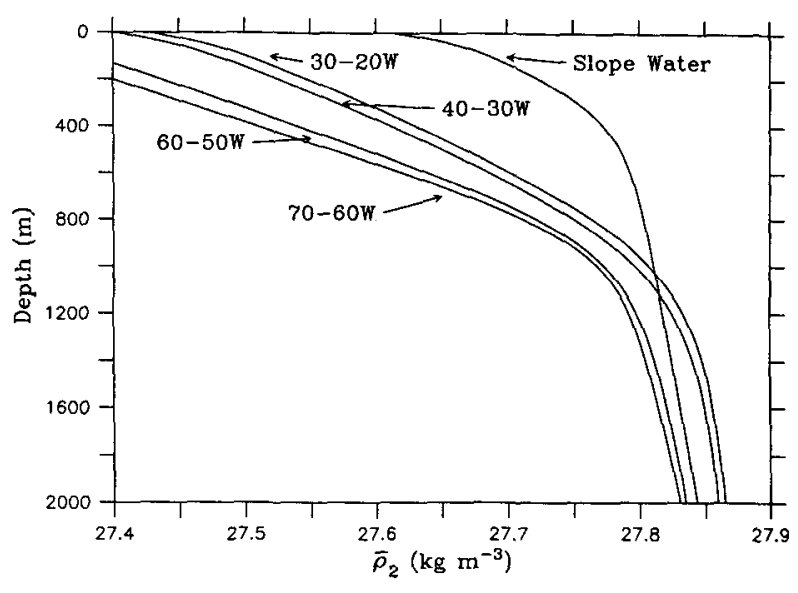

FlG. 6. Mean lower layer density $\left(\bar{\rho}_{2}\right)$ as a function of selected interface depth across the North Atlantic in the $30^{\circ}-34^{\circ} \mathrm{N}$ midlatitude band.

to the interface for the upper layer and from the interface to the bottom of the mean profile $(2000 \mathrm{~m})$ for the lower layer. Figure 6 shows the estimate of $\bar{\rho}_{2}$ as derived from the mean profiles as a function of the depth selected for the interface for each of the eastwest boxes. Since there was only one cast in the $40^{\circ}-$ $50^{\circ} \mathrm{W}$ region, this region was not used for our analysis. The depth-averaged density of the water column from the surface to $2000 \mathrm{~m}$ in the slope water box is 27.61 . Following the argument presented at the beginning of this section, this is then taken as $\bar{\rho}_{2}$. We could choose the depth at which $\tilde{\rho}_{2}$ attains the value of 27.61 in different regions as the interface between the two layers. Alternatively, the potential density $\left(\sigma_{\theta}\right)$ at which $\bar{\rho}_{2}$ attains the value of 27.61 (recall that $\bar{\rho}_{2}$ is the average density from $2000 \mathrm{~m}$ to the interface) could be obtained for each of the five regions, and a representative value chosen from these five values could be used to define the interface. This is in fact the approach taken here, in that it is more meaningful physically and less sensitive to the total depth of the cast $(2000 \mathrm{~m})$. Admittedly, extending the profiles to depths of 3000 or 4000 $\mathrm{m}$ will result in a larger value of $\bar{\rho}_{2}$, but estimates of this difference suggest at most a $10 \%-15 \%$ decrease in the reduced gravity parameter and a very small effect on the density surface of the interface, that is, $h_{\mathrm{e}}$. We therefore feel that the additional effort and uncertainty in extending the profiles beneath $2000 \mathrm{~m}$ is not warranted. Furthermore, the theory holds dynamically as long as the upper layer is much thinner than the lower layer for the two-layer model in question. In Fig. 7, the potential density, $\sigma_{\theta}$, corresponding to the calculated $\bar{\rho}_{2}$ is shown for each of the five regions across the North Atlantic as a function of $\bar{\rho}_{2}$, both of which are determined from the interface depth. The average $\sigma_{\theta}$ for $\bar{\rho}_{2}=27.61$ (excluding the slope water) is found to be $26.85 \mathrm{~kg} \mathrm{~m}^{-3}$, and this density surface is chosen as the representative pycnocline of our two-layer model. 


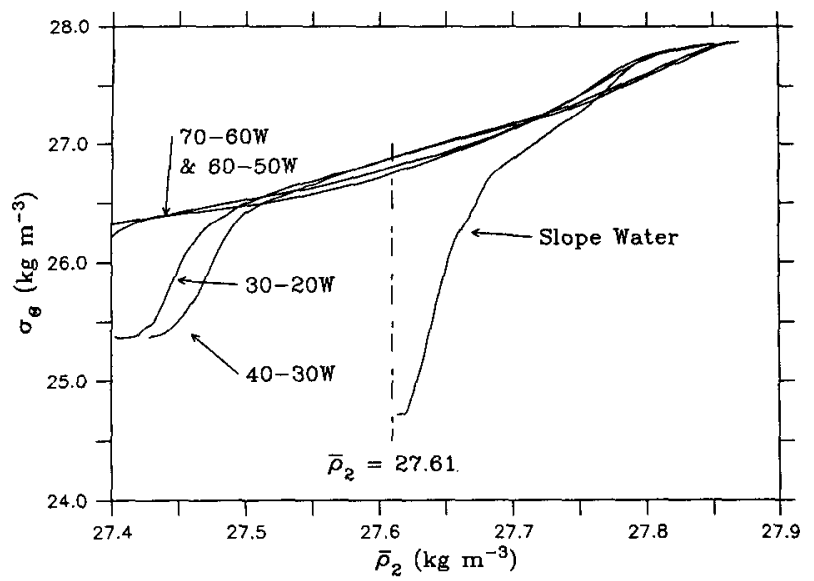

Fig. 7. Potential density $\left(\sigma_{\theta}\right)$ at the interface as a function of the mean lower-layer density $\left(\bar{\rho}_{2}\right)$ for each of the five boxes analyzed; $\sigma_{\theta}$ and $\bar{\rho}_{2}$ are determined from the selected interface depth.

The depth of the $\sigma_{\theta}=26.85$ surface across the basin is shown in Fig. 8. Now using $\sigma_{\theta}=26.85$ to define the interface, $\bar{\rho}_{1}$ is then determined from $\sigma_{\theta}$ averaged across the basin as shown in Fig. 9. The average value of $\bar{\rho}_{1}$ (excluding the slope water) for $\sigma_{\theta}=26.85$ is found to be 26.4. Note that the surface front observed from the satellite data may not coincide with the 26.85 potential density surface but is expected to be parallel to it (Cornillon and Watts 1987; Hansen and Maul 1970). Now that a density interface has been defined for the interface of our two-layer model ocean and the average densities of the upper and the lower layer, $\bar{\rho}_{1}$ and $\bar{\rho}_{2}$, respectively, have been obtained, we may determine the values of $g^{\prime}$ and $h_{\mathrm{e}}$. For these average densities, the reduced gravity, $g^{\prime}=g\left(\bar{\rho}_{2}-\bar{\rho}_{1}\right) /\left(1000+\bar{\rho}_{2}\right)$ $=0.0115 \mathrm{~m} \mathrm{~s}^{-2}$. The variation of $g^{\prime}$ with $\sigma_{\theta}$ for regions across the North Atlantic is shown in Fig. 10a. The full range of $g^{\prime}$ for the selected regions ranges from 0.0105 to $0.012 \mathrm{~m} \mathrm{~s}^{-2}$, but all the regions are well represented by the chosen $\sigma_{\theta}, g^{\prime}$ values.

\section{b. Meridional variation of the thickness of the upper layer $\left(h_{e}\right)$ in the eastern North Atlantic}

Because the Gulf Stream is observed to separate between approximately $35^{\circ}$ and $37.5^{\circ} \mathrm{N}$, we require $h_{\mathrm{e}}$

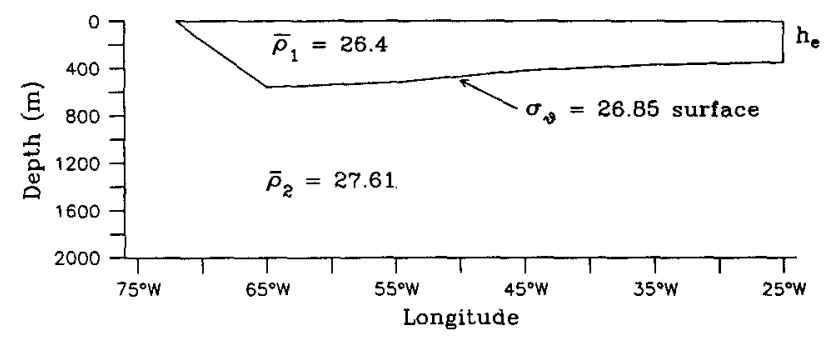

FIG. 8. The two-layer representation of the North Atlantic as adopted for this study based on available CTD data.

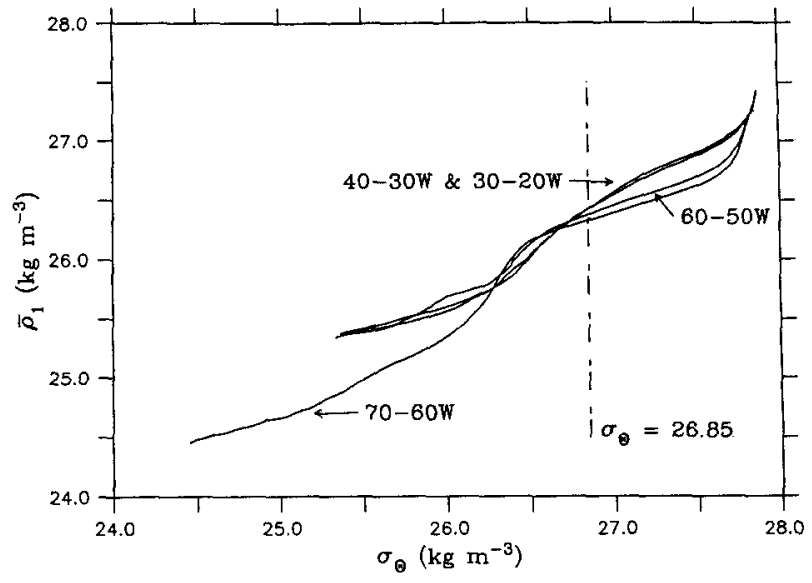

FIG. 9. Mean upper-layer density $\left(\bar{\rho}_{1}\right)$ as a function of the chosen potential density $\left(\sigma_{\theta}\right)$ interface for each of the four analysis regions across the North Atlantic.

as a function of latitude in this range. Earlier analytical studies based on a two-layer ocean have tended to keep this parameter constant on the eastern side of the basin; that is, north-south variations of this parameter were not allowed (Pedlosky 1987; Huang and Flierl 1987).
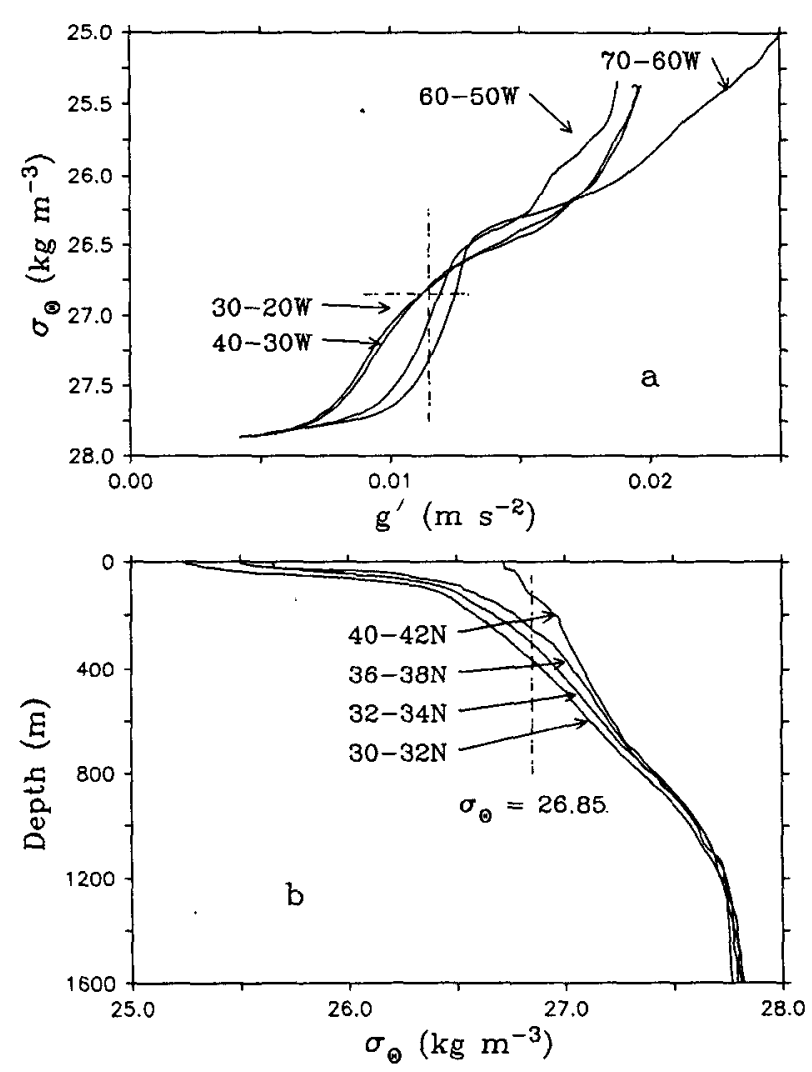

FIG. 10. (a) The variation of $g^{\prime}$ as a function of the choice of potential density, $\sigma_{\theta}$. The dashed lines indicate the chosen interface and $g^{\prime}$. (b) Vertical profiles of potential density $\left(\sigma_{\theta}\right)$ at different latitudes in eastern North Atlantic $\left(20^{\circ}-30^{\circ} \mathrm{W}\right)$. 
Here, a north-south sloping interface is allowed on the eastern side of the North Atlantic. To obtain this function, we selected six $10^{\circ}$ longitude by $2^{\circ}$ latitude boxes between $30^{\circ}$ and $42^{\circ} \mathrm{N}$ for the easternmost longitudinal band in our study area (Fig. 5). The longitude range selected for these boxes clearly does not lie on the eastern side of the basin as required by the Parsons-Veronis model. The east-west slope of the $\sigma_{\theta}=26.85$ surface is, however, sufficiently close to zero east of $35^{\circ} \mathrm{W}$ (Fig. 8 ), so that the error made in using values from this region as representative of $h_{\mathrm{e}}$ is small. More importantly, by this choice the significant perturbation of the density interface resulting from the Mediterranean salt tongue is avoided. For the four boxes with more than two CTD casts in our dataset, we calculated a mean density profile as was done for the east-west boxes. These are shown in Fig. 10b. The north-south slope of the $\sigma_{\theta}=26.85$ interface is $0.24 \times 10^{-3}$, obtained by least-squares fitting the interface depths available from Fig. 10b across latitudes. Figure 11 a shows the depth of the two-layer model interface as a function of latitude in the eastern North Atlantic as well as the actual depths as obtained from Fig. 10b. The depth of the interface determined here agrees reasonably well with the historical atlas of Fuglister (1960).

Finally, the north-south slope of the interface shown in Fig. $11 \mathrm{a}$ is compared with the slope of density surfaces at a similar depth estimated by Stramma (1984b) from two long CTD sections. Stramma (1984a) reported that between the Azores and the west coast of Africa, nearly half of the eastward transport of the 0$800-\mathrm{m}$ layer is carried in the upper $200 \mathrm{~m}$. As determined from two long CTD sections taken on RV $\mathrm{Me}$ teor cruise 60 (Fig. 8 of Stramma 1984b), the eastward velocity in the $35^{\circ}-37.5^{\circ} \mathrm{N}$ region at the $26.5 \mathrm{~kg} \mathrm{~m}^{-3}$ potential density surface is on the order of 0.02-0.04 $\mathrm{m} \mathrm{s}^{-1}$. He obtained a level of no motion at $1200 \mathrm{~m}$ by using the dynamic method in association with the conservation of mass scheme as employed by Fiadeiro and Veronis (1982). This range of geostrophic velocities yields a range for the north-south slope of the thermocline in the eastern Atlantic of $0.18-0.36\left(\times 10^{-3}\right)$ with an assumed $g^{\prime}$ of $0.0115 \mathrm{~m} \mathrm{~s}^{-2}$. Therefore, the north-south slope of the thermocline in our analysis, $\left(0.24 \times 10^{-3}\right)$, is consistent with the observed geostrophic velocities in the eastern North Atlantic.

Given the free parameters, $g^{\prime}$ and $h_{\mathrm{e}}$, the geostrophic transport term in (8) can be evaluated as a function of latitude. This term, $T_{\mathrm{g}}=g^{\prime} h_{\mathrm{e}}^{2} / 2 f$, is plotted against latitude, as shown in Fig. $11 \mathrm{lb}$. Note that we do not have enough data to evaluate the temporal variation of this term over the period of study. Stramma and Siedler (1988) observed weak seasonal variability of the upper 200-m transport in the eastern North Atlantic and concluded that the interannual variability could not be studied because of lack of observations. The seasonal variability of $h_{\mathrm{e}}$ and $g^{\prime}$ are well within the observational error bounds as described in the Appendix. Thus, for
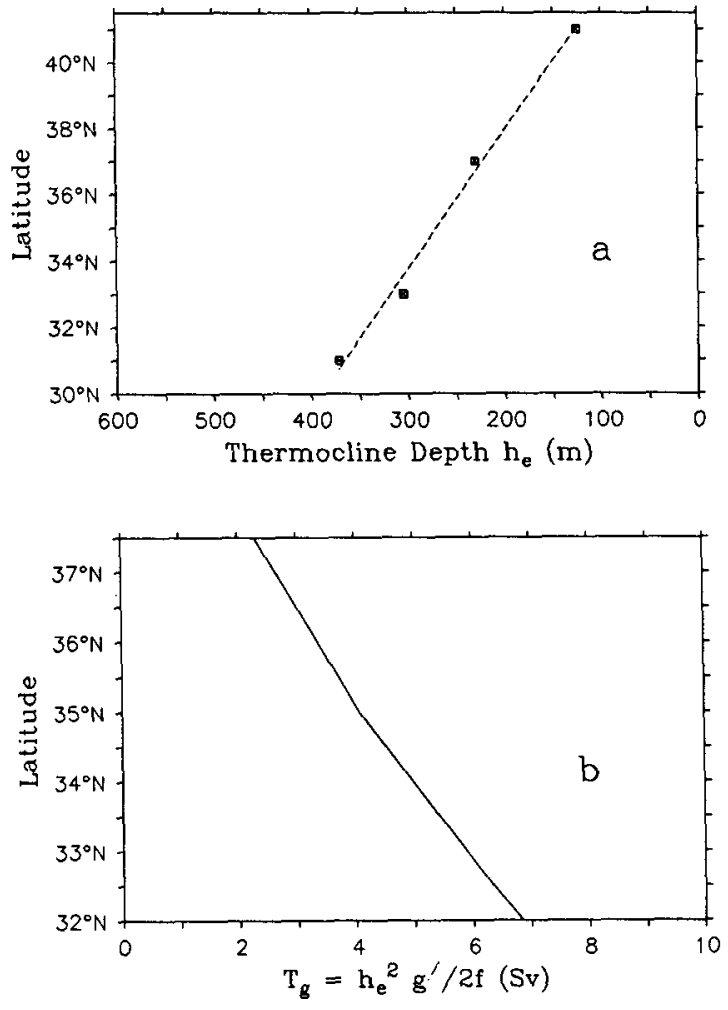

FIG. 11. (a) Depth of the 26.85 potential density surface as a function of latitude obtained from the density profiles shown in Fig. 10b with the linear best-fit line. (b) Variation of the geostrophic transport term $\left(T_{\mathrm{g}}\right)$ with latitude.

this study, the intersection of the $T_{\mathrm{g}}$ versus latitude curve in Fig. $11 \mathrm{~b}$ with the annual $T_{\mathrm{E}}$ versus latitude curves in Fig. 4 yields the predicted latitude of separation according to the Parsons-Veronis hypothesis.

\section{Results and discussion}

\section{a. Predictions versus observations}

As discussed in section 3 , observationally the latitude of separation is defined as the intersection of the Gulf Stream mean annual path with the 2000 -m isobath (Fig. 4a). The corresponding latitude predicted by the Parsons-Veronis model is, on the other hand, determined from the intersection of the $T_{\mathrm{g}}\left(=g^{\prime} h_{\mathrm{e}}^{2} / 2 f\right)$ versus latitude curve (Fig. $11 \mathrm{~b}$ ) with the $T_{\mathrm{E}}$ versus latitude curve (Fig. 3). The annual predicted latitude of separation is plotted as a time series in Fig. $4 \mathrm{~b}$ as shown by the dashed line. The same annual predicted outcropping latitudes are also plotted against the observed annual separation latitudes in Fig. 12a. Since the twolayer model ocean is baroclinic in its response, we did not expect a perfect correlation between theory and observation for the annual time scale. The baroclinic time scale for a planetary wave to cross the North Atlantic is on the order of years to decades (Anderson 

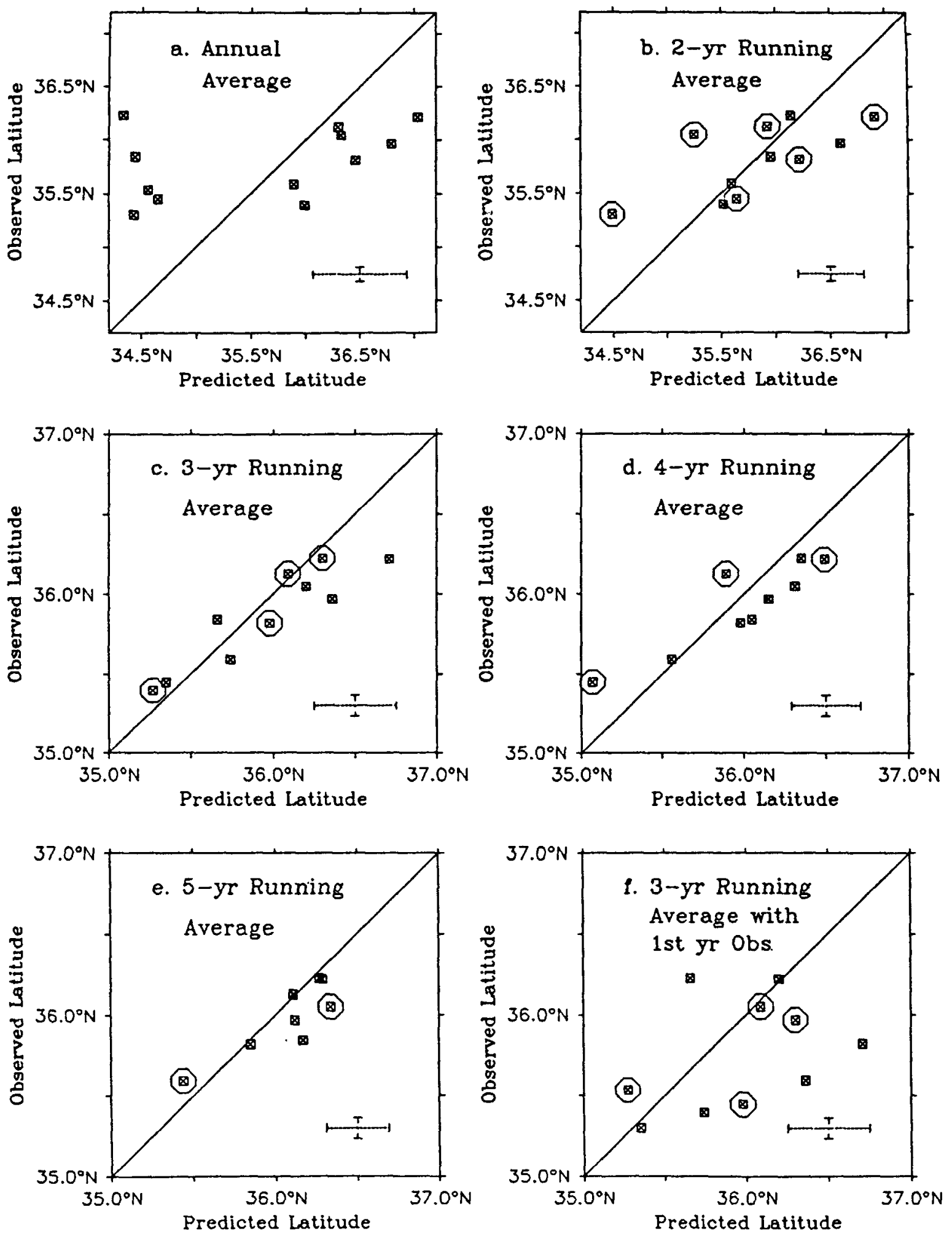

FIG. 12. Predicted latitudes versus observed latitudes for separation of the Gulf Stream for different averaging time periods: (a) annual; (b) 2-year running average; (c) 3-year running average; (d) 4-year running average; (e) 5-year running average; and (f) 3-year running average with observations plotted for the first year of the averaging interval. The error bars indicate the geophysical errors associated with the observations and the predictions. (See the Appendix.) 
and Corry 1985). Recently, Halliwell and Cornillon (1990b) have investigated sea surface temperature and sea surface elevation anomalies in the subtropical convergence zone and found that the anomalies propagate westward at approximately $3.7 \mathrm{~km} \mathrm{day}^{-1}$. For the North Atlantic width of $5000 \mathrm{~km}$, this corresponds to a time scale on the order of $31 / 2$ years. By using the reduced gravity and thermocline depths as determined for the representative two-layer model, a rough estimate for the time taken by the first baroclinic mode planetary wave to cross the North Atlantic yields about 6 years.

Given the long time period ( $\geqslant 3$ years) for changes of the wind stress in the eastern portion of the basin to affect the transport in the west and, hence, the separation of the western boundary current, running means of 2, 3, 4, and 5 years were calculated from the 12 annual averages of wind stress. The Parsons-Veronis predicted latitudes of separation are calculated using each new mean. For example, in the case of 3-year running average, the zonal wind stress over the analysis domain is averaged over a 3-year period then integrated across the Atlantic every $2.5^{\circ}$ latitude to yield a new $T_{\mathrm{E}}$ versus latitude curve; intersection of this curve with the $T_{\mathrm{g}}$ versus latitude curve determines the predicted latitude of separation. Then we proceed to the next year and perform a similar analysis for the next 3 years. Thus, for a 3-year running average, every fourth point yields an independent prediction.

As discussed earlier, the underlying mechanism by which information regarding variation in the wind stress over the central ocean affects the western boundary is planetary waves. In the following, we present our investigation to identify the optimal time-lag and averaging period that are associated with the planetary wave mechanism. First, a lagged correlation between the predictions and the observations was performed for different averaging intervals. The annual-, 2-year, and 3-year averaged predictions were correlated with observations of up to 3 years lag. As shown in Table 2 , the correlation coefficient increases for the 3-year lag for all of the averaging intervals. The $r^{2}$ values beyond the tabulated range were not reported either because there were not enough degrees of freedom (for 4- and 5-year averaging intervals) or because the obtained correlation values were much less than the 3 year lag value (for 1-, 2-, and 3 year averaging intervals). The squared correlation $\left(r^{2}\right)$ of the predicted versus observed latitudes increases from 0.18 for the annual average to 0.91 for the 3 -year running average.

Furthermore, the observed separation latitude for the last year of the averaging interval is also plotted against the corresponding predictions in Fig. 12. The observation corresponding to the last year of the averaging interval was used in this comparison to accommodate the traveling planetary wave mechanism. For example, for a 4-year running average starting at 1981, the prediction is based on the averaged zonal wind stress for the period 1981-84; whereas the observed
TABLE 2. The $R^{2}$ values from the lag-correlation analysis.

\begin{tabular}{cccc}
\hline & \multicolumn{3}{c}{ Lag (years) } \\
\cline { 2 - 4 } $\begin{array}{c}\text { Averaging interval } \\
\text { (years) }\end{array}$ & 1 & 2 & 3 \\
\hline 1 & 0.18 & 0.21 & 0.56 \\
2 & 0.11 & 0.49 & 0.76 \\
3 & 0.16 & 0.48 & 0.91 \\
\hline
\end{tabular}

separation latitude is averaged over 1984 only. The 3year predicted latitudes of separation are plotted as a time series in Fig. $4 c$ to serve as a comparison with the observations as well as with the annual predictions. Apart from increasing correlation for larger averaging intervals (as shown in Fig. 12 and tabulated in Table 2 ), the slope of the linear-fit regression line also increases from $0.14( \pm 0.09)$ for the annual averaging period to $0.61( \pm 0.09)$ for the 3-year running-average period. A statistical analysis to justify the goodness of fit of these regression lines is presented separately in section $5 \mathrm{c}$.

It is, however, conceivable that the depth of the interface on the eastern portion of the ocean responds to changes in wind forcing, in which case an equally dramatic improvement of the fit between the observed and the predicted values would result if the observed separation corresponding to the first year of the averaging interval were used. Figure $12 \mathrm{f}$ shows such a plot in which the 3-year running-averaged predictions are plotted against the first year of observations. The value of $r^{2}$ is only 0.16 (statistically insignificant) as compared with 0.91 for the 3-year running-average period. The slope of the linear-fit regression line for this case $(0.3 \pm 0.24)$ is also statistically insignificant, that is, indistinguishable from zero. So, both the results of the lag-correlation (Table 2) and the correlations plots in Fig. 12 suggest that: 1) Parsons-Veronis hypothesis is a good predictor of the separation of the western boundary current, that is, the hypothesis contains the basic physics; and 2) changes in transport of the western boundary current that alter the point of separation are coupled to the wind stress via planetary waves propagating from east to west across the Atlantic at speeds on the order of $4 \mathrm{~km} \mathrm{day}^{-1}$.

\section{b. Distribution of $\tau_{x}$ across North Atlantic}

As discussed in detail earlier, the contribution of the zonal wind stress to the point of separation is determined by integrating the zonal wind stress across the Atlantic. Whatever zonal structure may be present is all integrated together to give a single $T_{\mathrm{E}}$ as a function of latitude. However, it is of interest to know if the wind stress from the eastern or western portion of Atlantic dominates that from the remainder of the basin, since it would affect the time required for the change to reach the western boundary. For example, if winds over the western third of the basin were to dominate, 
shorter temporal averages of the wind field would have been indicated. Dominance by winds from the eastern portion of the basin, on the other hand, would suggest a lag in the response rather than a temporal average, while a relatively homogeneous wind field would suggest temporal averaging as performed above.

To address these concerns we note again the observed temporal trend in the separation latitude during the study period $1977-88$ (Fig. 4b and c), specifically that the Gulf Stream separated farther to the north in later years (1983-85) than in earlier years (1977-79). Equation (9), taken together with the fact that $h_{\mathrm{e}}$ decreases with latitude, suggests that larger (smaller) values of $T_{\mathrm{E}}$ result in a more southerly (northerly) point of separation. Because the 3-year predictions give the best agreement with observations, the zonal wind stress anomalies for each of the four independent 3-year periods (i.e., for 1977-79, 1980-82, 1983-85, and 198688 ) are computed (Fig. 13). These anomaly fields are derived from the differences between the respective 3year average fields and the 12-year mean field of the zonal wind stress over the North Atlantic basin. As shown in Fig. 13, the anomaly field is mostly positive (negative) in the early (later) years, contributing toward larger (smaller) than average values of the integrated Ekman drift $\left(T_{\mathrm{E}}\right)$ and thus, under the Parsons-Veronis hypothesis, resulting in a lower (higher) latitude of separation. Recalling that it takes time for the signal to cross the Atlantic from east to west, each 3-year averaging interval for the zonal winds should be compared with the latitude of separation for the last year of the corresponding averaging interval.

The anomaly field for $1977-79$ (Fig. 13a) is high everywhere across the basin between $30^{\circ}$ and $40^{\circ} \mathrm{N}$, resulting in a lower latitude of separation for 1979. For 1980-82 (Fig. 13b), the anomaly field is high on the western half of the basin and low in the eastern half of the basin; thus, the integral is very close to zero and the latitude of separation for 1982 is about the average for the 12-year study period. On the other hand, the wind-stress anomaly field for 1983-85 (Fig. 13c) is low across most of the basin, resulting in a separation point farther to the north. For 1986-88 (Fig. 13d), the anomaly field is also low over most of the basin. Although the overall anomaly field structure between $35^{\circ}$ and $40^{\circ} \mathrm{N}$ for the period of $1986-88$ is different from that of 1983-85 period, the values of the integrated Ekman wind drift are not much different for these two averaging intervals, and the observed latitude of separation differs only by $15 \mathrm{~km}$ between 1988 and 1985 . These observations of the anomaly field behavior suggest that no part of the Atlantic contributes a disproportionately large fraction to the integrated Ekman transport.

\section{c. Error estimates}

As described in section 4, the estimates of $g^{\prime}$ and $h_{\mathrm{e}}$ depend on the available CTD data and thus are subject to geophysical variability. Such geophysical errors are estimated in the prediction of the latitude of separation using the variability obtained from the calculated potential densities for the CTD sections. Error bars so obtained are shown in Fig. 12 and are discussed in detail in the Appendix. In this subsection, we investigate the statistical significance of the linear-fit regression lines between the predicted latitude of separation and the observed latitude of separation for different averaging intervals.

Since the numbers of independent predictions decrease as the averaging interval for the 12-year dataset increase, a linear regression analysis is performed only on the independent values. The set of independent points for each plot are indicated by circles in Fig. 12. For the annual averages however, all 12 pairs are independent. The values of the squared correlation $\left(r^{2}\right)$ for these independent datasets are presented in Fig. $14 \mathrm{a}$ for $1,2,3$, and 4 years of averaging. The 5-year averaging resulted in only two independent samples and therefore was excluded from the regression analysis. Note that $r^{2}$ increases from 1- to 3-year averaging and then remains virtually unchanged at a value quite close to unity for the 4-years of averaging. The increase in $r^{2}$ from 0.18 to 0.92 as the averaging interval increases suggests a statistically better fit to the data but does not answer the question of whether or not the fits are statistically significant. To determine this, we performed a Student's $t$-test on each of the curves, where the hypothesis being tested that $\beta=1$, where $\beta$ is the slope of the regression line, $y=\alpha+\beta x, y$ is the observed separation latitude, and $x$ is the predicted separation latitude. The results of this test are summarized in Table 3. The standard deviation of the predictions $\left(S_{x}\right)$ reduces from $98 \mathrm{~km}$ for the annual period to $45 \mathrm{~km}$ for the 3-year period. The standard deviation for the observation $\left(S_{y}\right)$ is not affected much by the time period chosen, which selects different subsets of independent choices of the annual averages. Note that these standard deviations are calculated based on the temporal variability of the points in the independent datasets and are in no way related to the error bars evaluated earlier using geophysical variability and shown in Fig. 12. The hypothesis $\beta=1$ is tested by evaluating $t=(b-1)$ / $S_{b}$ for each case, where $b$ is the calculated regression slope. Here $S_{b}$ is given by $S_{b}^{2}=S_{Y, X}^{2} /(n-1) S_{x}^{2}$, where $S_{Y . X}$ is the measure of the dispersion of the data about the regression line as evaluated from the relation: $S_{Y, X}^{2}=[(n-1) /(n-2)]\left(S_{y}^{2}-b^{2} S_{x}^{2}\right)$. At the $95 \%$ significance level, we found that the hypothesis $\beta=1$ is rejected for the annual and the 2-year averaging intervals, whereas the regression slopes are not significantly different from unity for the 3- or 4-year independent datasets. The $95 \%$ confidence intervals on the slopes are shown in Fig. 14a. We did not plot the confidence interval for the 4-year analysis because there are only two degrees of freedom for this case. A similar test was performed using standard deviations $\left(S_{x}\right.$ and 


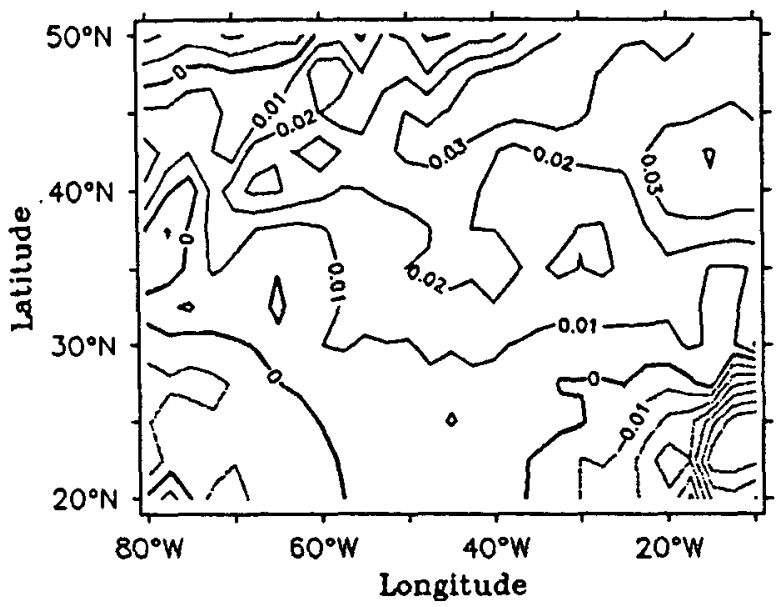

a. $1977-79$

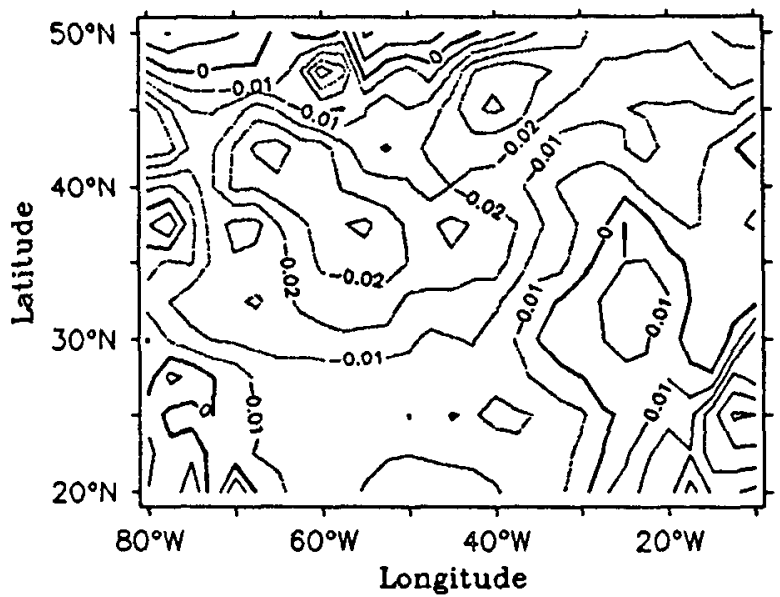

c. $1983-85$

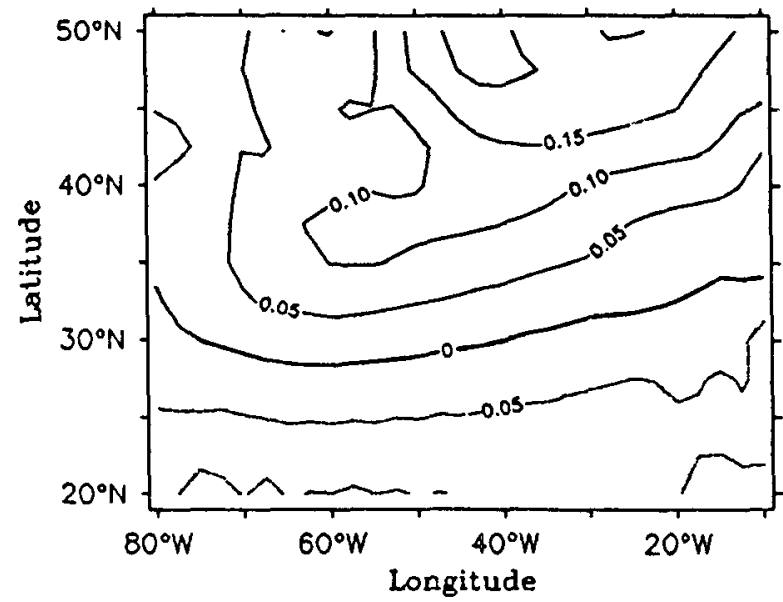

e. $\left\langle\tau_{x}\right\rangle$

Fig. 13. Zonal wind-stress anomalies, $\tau_{x}-\left\langle\tau_{x}\right\rangle$, over the North Atlantic midlatitude region for the four 3-year independent sets of observations; $\tau_{x}$ is averaged for: (a) $1977-79$, (b) $1980-82$, (c) 1983-85, and (d) 1986-88. Panel (e) $\left\langle\tau_{x}\right\rangle$ is the 12-year average zonal wind stress. Contour units: $\mathrm{N} \mathrm{m}^{-2}$.

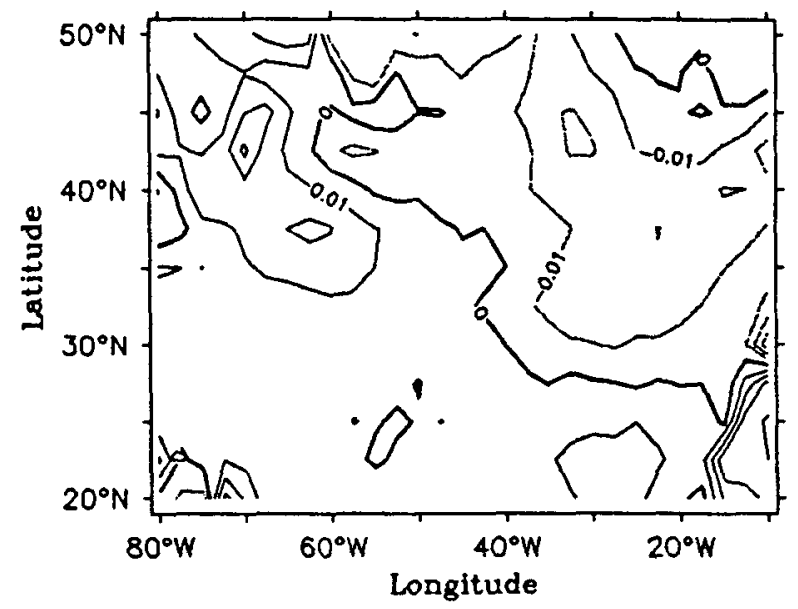

b. $1980-82$

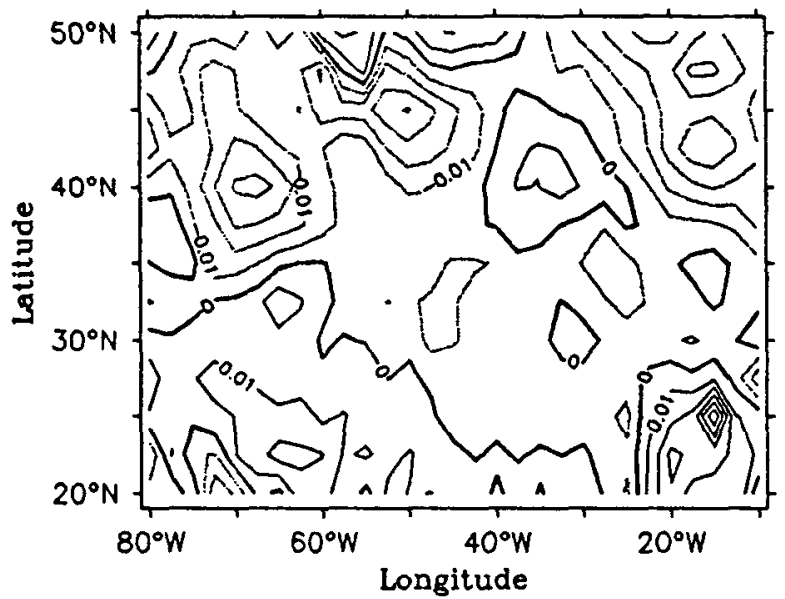

d. $1986-88$ 

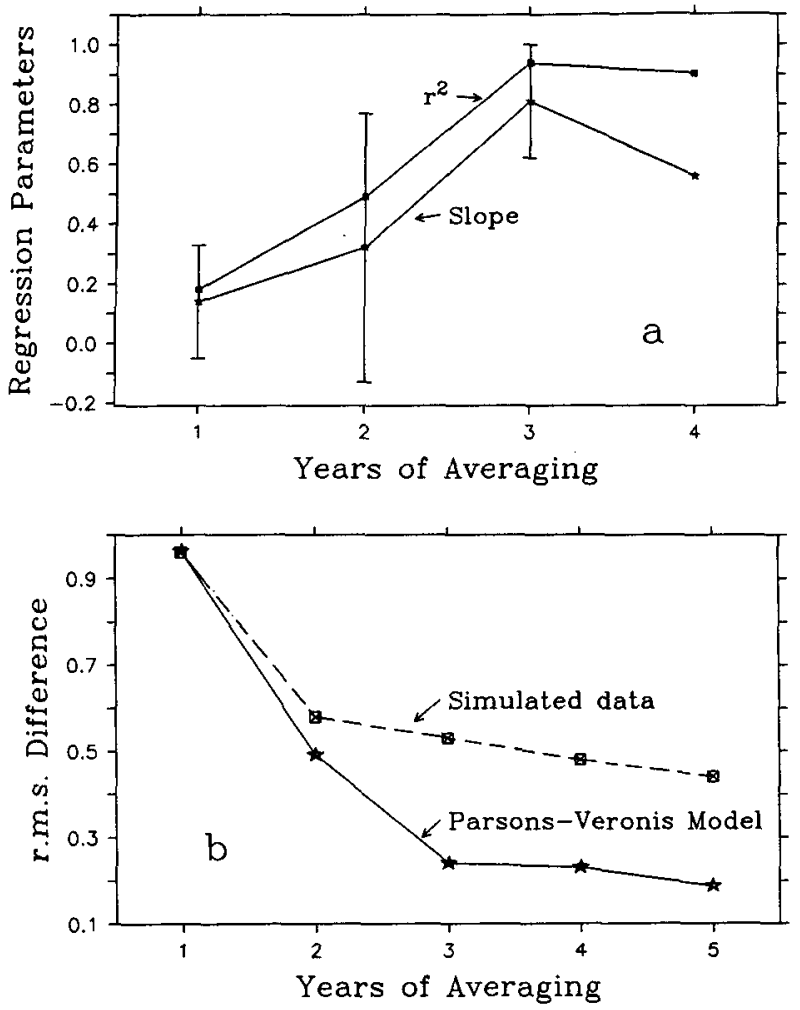

FIG. 14. (a) The squared correlation $\left(r^{2}\right)$ and the linear regression slope are shown to be increasing with increasing number of years of averaging. The error bars apply to the slope. (b) Rms difference between the predicted and the observed separation latitudes as a function of the averaging time (solid line). The dashed line represents corresponding improvement for simulated data as described in section $5 \mathrm{~d}$.

$S_{y}$ ) equal to the errors, as shown in Figs. 12a-d. These geophysical errors are about one-half as large as the actual spread of the data used above. This analysis also resulted in rejection of the 1- and 2-year averages and in slopes indistinguishable from unity for the 3- and 4-year averages.

\section{d. On the time scales of averaging}

As discussed above, the agreement between observations and predictions increases with increasing number of years of averaging the Ekman drift. The dynamical reason attributed to such improvement is the time taken by long baroclinic planetary waves to cross the Atlantic. For each period of averaging, the rms difference between the observation and the prediction is evaluated by $\left.\sum_{i=1}^{N}\left(L_{\mathrm{oi}}-L_{\mathrm{pi}}\right)^{2} / N\right)^{1 / 2}$, where $L_{\mathrm{oi}}$ and $L_{\mathrm{pi}}$ are the observed and the predicted latitudes for the $i$ th year. This is shown in Fig. 14b. The rms difference decreased from $0.96^{\circ}$ for the annual average to $0.19^{\circ}$ for the 5 -year average. Similarly, a decrease was found in the scatter, as illustrated by the increase of the value of the squared correlation coefficient shown in Fig. 14a. The fairly dramatic break in the curve of $r^{2}$ versus averaging interval at 3 years with little change in $r^{2}$ for the 4-year averaging suggests that the time taken by the North Atlantic to respond to wind forcing is on the order of 3 years for this simple two-layer model ocean.

Note that the rms difference between the observed and the predicted values will decrease with averaging interval simply because the range of predictions is initially twice that of the observations, even if the data were purely random. Since the perceived signal is red (Fig. 4), we simulated 50 time series of 12 predictionobservation pairs that had the same spectra as the 12year predicted and observed time series, respectively. Then we performed running averages of these, as was done with the real data, and computed the rms difference for each case. The mean rms improvement of the 50 simulations is also shown in Fig. 14b, indicated by the dashed line. Clearly, the improvement achieved by the red-noise simulated data is much smaller than that observed. This is taken as strong evidence supporting the Parsons-Veronis model.

\section{e. On the difference between the predictions and the observations}

Finally, the predicted points of separation were obtained by assuming a closed basin to the north and no loss of fluid from the upper to the lower layer is noted. Therefore, contributing to the difference between the observed and predicted values is the loss of fluid from the upper layer at higher latitudes. In fact, within the constraints of this model the interannual variability in the loss of fluid from the upper layer is able to be bound through a statistical analysis of our results.

By substituting $T_{\mathrm{g}}$ in place of $g^{\prime} h_{\mathrm{c}}^{2} / 2 f$ in (8),

$$
T_{1}=T_{\mathrm{g}}-T_{\mathrm{E}}
$$

is obtained. This equation states that the difference between the geostrophic transport and the Ekman drift at the observed latitude $\left(T_{\mathrm{E}}\right)$ determines the net northward transport in the upper layer across that latitude. Since the Parsons-Veronis hypothesis agrees well with observations for the 3-year averaging period, we estimated this net northward transport from the dataset as presented in Fig. 12c. For this ten-point dataset, the mean value of $T_{1}$ is determined as $0.1 \mathrm{~Sv}\left(\mathrm{~Sv} \equiv 10^{6}\right.$ $\mathrm{m}^{3} \mathrm{~s}^{-1}$ ) with a standard deviation of $0.18 \mathrm{~Sv}$. Within the possible range of values of $g^{\prime}$ and $h_{\mathrm{e}}$ (Figs. 10 and 11 ), this estimate of $T_{1}$ could be as high as $4 \mathrm{~Sv}$ with

TABLE 3. Results of $t$ test for $\beta=1$. DF: degrees of freedom.

\begin{tabular}{ccccccc}
\hline \hline $\begin{array}{c}\text { Years of } \\
\text { averaging }\end{array}$ & $\begin{array}{c}n(\mathrm{DF}) \\
\mathrm{DF}=(n-2)\end{array}$ & $\begin{array}{c}S_{x} \\
(\mathrm{~km})\end{array}$ & $\begin{array}{c}S_{y} \\
(\mathrm{~km})\end{array}$ & $\begin{array}{c}\text { Slope } \\
(\beta)\end{array}$ & $t$ & $\begin{array}{c}H_{0}: \beta=1 \\
\text { rejected at } \\
95 \%\end{array}$ \\
\hline & $12(10)$ & 98 & 32 & 0.18 & -9.52 & Yes \\
2 & $6(4)$ & 83 & 38 & 0.32 & -4.15 & Yes \\
3 & $4(2)$ & 45 & 37 & 0.81 & -1.78 & No \\
4 & $3(1)$ & 71 & 42 & 0.56 & -2.31 & No \\
\hline
\end{tabular}


similar associated uncertainties. This is a surprisingly low estimate of $T_{1}$ and possibly a limitation of the simple two-layer dynamics, which does not allow for processes that could exchange waters between the two layers, such as cross-frontal exchange, ring formation, and subduction.

\section{Conclusions}

Observations of the point at which the Gulf Stream leaves the continental margin in conjunction with observed basinwide wind stresses are used to test the Parsons-Veronis hypothesis. CTDs available from the NODC database for the North Atlantic are used to define a representative two-layer model. The northsouth slope of the resulting interface on the eastern margin of the basin compares well with that obtained from two long CTD sections covering roughly the same region. Veronis (1973) suggested that the position at which the stream leaves the coast results from a balance between the Ekman drift and geostrophic flow. Using 12 years of wind and satellite data over the period from 1977 to 1988 , we find that the latitude of separation as predicted by the Parsons-Veronis model agrees well with the observed separation latitudes for 3 or more years of averaging. We believe that the propagation of long baroclinic planetary waves plays a significant role in establishing the steady state for a simple two-layer model, and thus the 3-year period of averaging, which yields predictions of the latitude of separation that correlate well with those observed at the end of each 3year period, is dynamically consistent. Little improvement is found when the period of integration for the Ekman drift is increased beyond 3 years.

Observations presented in this work quantitatively support the Parsons-Veronis mechanism for the western boundary current separation of the Gulf Stream from the North American continent. By mid 1992, the AVHRR "PATHFINDER" dataset providing SSTs on a 9-km global grid should become available. This dataset, taken with the global wind fields generated numerically either by the U.S. Navy (FNOC), the National Meteorological Center (NMC), or the European Centre for Medium-Range Weather Forecasts (ECMWF), should allow studies similar to that presented here for the other major western boundary currents such as the Kuroshio and Agulhas currents. In particular, the temporal variability of the integrated Ekman drift over Northern Pacific could affect the bimodality of the Kuroshio, which has been observed to persist for long periods of time.

Acknowledgments. This research was performed with support from the National Aeronautics and Space Administration (No. 957627) as part of the NSCAT program. All figures were generated using the interactive graphics package PLOT5, developed by Donald Denbo. We gratefully acknowledge two very useful discussions between the authors and Prof. George Veronis regard- ing the selection of free parameters. We would also like to mention the benefit of the continued support of the University of Miami group for the satellite-derived images from which the surface fronts were digitized.

\section{APPENDIX}

\section{Error Analysis}

There are two sources of error in the satellite-derived mean Gulf Stream paths. The first are referred to as measurement errors that are due to navigation, digitization, and variations of the surface-subsurface offset (Gilman 1989). The lateral (error in a lateral displacement of the path, the quantity of interest here) contribution of each of these three components is assumed to be statistically independent from the others with rms uncertainties of $9,13.5$, and $15 \mathrm{~km}$, respectively, for each 2-day composite. Approximately 150 (allowing for $20 \%$ cloud coverage) 2 -day composites have been used to calculate the annual average assuming that the navigation and digitization errors from one realization of the stream to the next are independent; the contribution to the variance of the annual average from these two components is $\left(9^{2} / 150\right) \mathrm{km}^{2}$ and $\left(13.5^{2} / 150\right)$ $\mathrm{km}^{2}$, respectively. On the other hand, the surface-subsurface offset variation is modulated by meanders with wavelengths on the order of $50 \mathrm{~km}$ and phase speeds on the order of $8 \mathrm{~km} \mathrm{day}^{-1}$ (Gilman 1989), which yields a decorrelation time scale of approximately 6 days and thus about 60 independent observations per year. This component therefore contributes $\left(15^{2} / 60\right)$ $\mathrm{km}^{2}$ to the variance of the annual mean. The combined measurement uncertainty in the annual mean lateral displacement from all three components is therefore on the order of $3 \mathrm{~km}$.

The second observational error arises from the highfrequency meandering and ring-stream interactions in the separation region near Cape Hatteras. These meanders have amplitudes on the order of $20 \mathrm{~km}$ with associated time scales of $\mathbf{3 0}$ days (Tracey and Watts 1986). By averaging over an annual period, the latter is reduced by a factor of $\sqrt{12}$, that is, to approximately $5.8 \mathrm{~km}$. So, the total observational error from measurement and eddy variability is approximately $6.5 \mathrm{~km}$. The error estimated for the observed latitude does not change in Figs. 12a-f because the observations are always averaged over annual periods.

For the predicted latitude, three sources of error arise from three different parameters: the reduced gravity parameter, $g^{\prime}$; the depth of the thermocline at the eastern end, $h_{\mathrm{e}}$; and the estimate of the zonal wind stress. A change in the reduced gravity parameter causes a bias in the $T_{\mathrm{g}}$ versus latitude curve. A change in $h_{\mathrm{e}}$ introduces a tilt and offset in the same curve. Errors in the wind-stress estimate, which are on the order of 20\% (Halliwell and Cornillon 1990a), give rise to changes in the shape of the $T_{\mathrm{E}}$ versus latitude curves. Since all three factors are important for establishing 
an error bound on the prediction and do not contribute in a linear fashion, the error for the predicted latitude is estimated quantitatively as follows.

From Eq. (9), which is used for predicting the latitude of separation, the contribution to the uncertainty in $h_{\mathrm{w}}^{2}$ from each of the three parameters may be estimated from $h_{\mathrm{e}}: 2 h_{\mathrm{e}} \Delta h_{\mathrm{e}}$; from $T_{\mathrm{E}}: 2 f / g^{\prime} \Delta T_{\mathrm{E}}$; and from $g^{\prime}: 2 f / g^{\prime 2}\left(T_{\mathrm{E}} \Delta g^{\prime}\right)$. Combining these, where independence is assumed, admittedly a somewhat weak assumption,

$\left(\Delta h_{\mathrm{w}}^{2}\right)^{2}=\left(2 h_{\mathrm{e}} \Delta h_{\mathrm{e}}\right)^{2}+\left(\frac{2 f}{g^{\prime}} \Delta T_{\mathrm{E}}\right)^{2}+\left(\frac{2 f}{g^{\prime 2}} T_{\mathrm{E}} \Delta g^{\prime}\right)^{2}$

Then this variation of $h_{\mathrm{w}}, \Delta h_{\mathrm{w}}^{2}$, is used in accordance with (9) to determine the error bounds for the predicted separation latitude.

The variation of the reduced gravity parameter, $\Delta g^{\prime}$, is determined from the distribution of this parameter across the basin as shown in Fig. 10a. For the selected potential density surface of $\sigma_{\theta}=26.85$, the standard deviation of $g^{\prime}$ is obtained as $6.3 \times 10^{-4} \mathrm{~m} \mathrm{~s}^{-2}$. To determine the variation of the Ekman wind drift term, $\Delta T_{\mathrm{E}}$, it is reasonable to assume that the atmospheric disturbances are correlated spatially over $1000 \mathrm{~km}$, and their temporal decorrelation scale is on the order of 2 days. Thus, for a $5000-\mathrm{km}$ wide basin, the annual averaging of the 6-hour wind stress values with $20 \%$ measurement error (Halliwell and Cornillon 1990a) yield a standard deviation of $0.67 \%$. Additionally, there could be a several percent bias in $\tau_{x}$ due to uncertainty in the drag coefficient, which would not average out in the same way. Fortunately, uncertainty of about $\pm 20 \%$ in the value of the drag coefficient introduces relatively small error in the estimated wind stress for wind speeds up to $11 \mathrm{~m} \mathrm{~s}^{-1}$ (Smith 1990). Probably the most important contribution to the uncertainty in this analysis is due to the estimate of the depth of the thermocline on the eastern boundary, $h_{\mathrm{e}}$, in that it appears as a squared quantity in the separation balance equation. Clearly, the choice of $h_{\mathrm{e}}$ is essentially governed by the choice of the density interface between the two layers. The variation of the potential density, $\sigma_{\theta}$, is evaluated as obtained from the available $36 \mathrm{CTD}$ casts in the two southernmost eastern boxes shown in Fig. 5. The depth variation of the standard deviation of $\sigma_{\theta}$ is presented for the upper $500 \mathrm{~m}$ in Fig. 15 . Note that the standard deviation increases abruptly from less than $0.1 \mathrm{~kg} \mathrm{~m}^{-3}$ to more than $0.4 \mathrm{~kg} \mathrm{~m}^{-3}$ in the upper $100 \mathrm{~m}$ of the water column. Since this increase is believed to be an artifact of the seasonal changes in the mixed layer and the depth of the thermocline is below this region, a value of $0.1 \mathrm{~kg} \mathrm{~m}^{-3}$ is selected as the standard deviation of the potential density. Now the variation of the thermocline depth with the potential density is obtained from the slope of the thermocline at the eastern region, as shown earlier in Fig. 10b. This

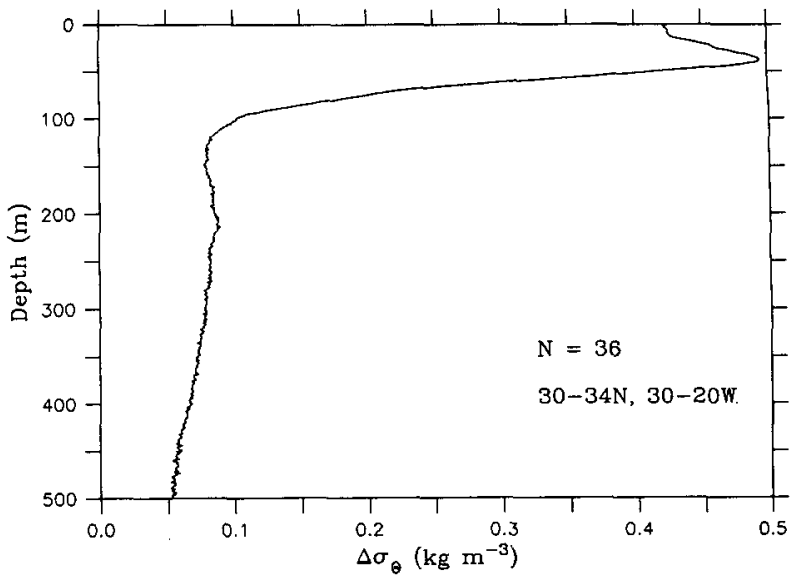

FIG. 15. The depth distribution of the standard deviation of the potential density for 36 CTD casts in the eastern North Atlantic.

slope, $\partial \sigma_{\theta} / \partial h=1.487 \times 10^{-3} \mathrm{~kg} \mathrm{~m}^{-4}$, results in an estimate of the variation of $h_{\mathrm{c}}$ of $67.24 \mathrm{~m}$. Since 36 independent CTD casts were used to obtain the variation of $\sigma_{\theta}$, and the independence of these casts is assumed, again a weak assumption, the standard error for the depth of the thermocline at the eastern boundary is determined to be $\Delta h_{e}=11.2 \mathrm{~m}$.

Once the variations of these three parameters are estimated, a representative value of $h_{\mathrm{e}}$, say $250 \mathrm{~m}$, is selected for which the error bars on the predicted latitudes will be evaluated. Using $h_{\mathrm{w}}=0$, for separation, in (9), the corresponding Ekman drift term is obtained as $T_{\mathrm{E}}=3.4 \mathrm{~Sv}$. Now, substituting the estimated parameter values into (11), a rms uncertainty for the square of the depth of the interface at the western boundary, $h_{\mathrm{w}}$, is obtained as $6431 \mathrm{~m}^{2}$. This variability of approximately $\pm 80 \mathrm{~m}$ in the thermocline depth at the western end corresponds to a $\pm 0.35 \mathrm{~Sv}$ variation in the Ekman drift from (9). In the latitudinal band of $35^{\circ}$ to $37.5^{\circ} \mathrm{N}$, the calculated slope of $0.812 \mathrm{~Sv} /{ }^{\circ} \mathrm{lat}$ from Fig. $11 \mathrm{~b}$ yields an estimated error for the annual predicted latitude of $43 \mathrm{~km}$. Averaging over $n$ years will reduce this value by a factor of $n^{1 / 2}$, as indicated in Figs. 12a-f. Note that these error bars are determined for a representative $h_{\mathrm{e}}=250 \mathrm{~m}$ and will change very little for each individual point; for example, a similar analysis with $h_{\mathrm{e}}=225 \mathrm{~m}$ yields an uncertainty in the annual prediction of $40 \mathrm{~km}$.

\section{REFERENCES}

Anderson, D. L. T., and R. A. Corry, 1985: Ocean response to lowfrequency wind forcing with applications to the seasonal variation in the Florida Straits-Gulf Stream transport. Progress in Oceanography, Vol. 14, Pergamon, 7-40.

__, K. Bryan, A. E. Gill, and R. C. Pacanowski, 1979: The transient response of the North Atlantic: Some model studies. J. Geophys. Res., 84, 4795-4815.

Bisagni, J. J., and P. Cornillon, 1984: The synoptic sound-speed field of a warm-core Gulf Stream ring. J. Acoust. Soc. Amer., 76, 532-539. 
Bryan, K., 1969: A numerical method for the study of the circulation of the World Ocean, 1969. J. Comput. Phys., 4, 347-376.

Cornillon, P., and D. R. Watts, 1987: Satellite thermal infrared and inverted echo sounder determinations of the Gulf Stream northern edge. J. Atmos. Oceanic Technol., 4, 712-723.

- - C. Gilman, L. Stramma, O. Brown, R. Evans, and J. Brown, 1987: Processing and analysis of large volumes of satellite-derived thermal infrared data. J. Geophys. Res., 92, 12 993-13002.

Craig, H., W. S. Broecker, and D. Spencer, 1981: Geosecs Atlases, Vol. 1-4. National Science Foundation, 1-198.

Fiadeiro, M. E., and G. Veronis, 1982: On the determination of absolute velocities in the ocean. J. Mar. Res., 40(Suppl.), 159192.

Fuglister, F. C., 1960: Atlantic Ocean Atlas. Woods Hole Oceanographic Institution, 1-209.

Gill, A. E., 1982: Atmosphere-Ocean Dynamics. Academic Press, $662 \mathrm{pp}$.

Gilman, C., 1989: A study of the Gulf Stream downstream of Cape Hatteras 1975-1986. M.S. thesis, University of Rhode Island, $75 \mathrm{pp}$.

Greenspan, H. P., 1962: A criterion for the existence of inertial boundary layers in oceanic circulation. Proc. Natl. Acad. Sci., 48, 2034-2039.

Halliwell, G. R., and P. Cornillon, 1990a: Large-scale SST variability in the western North Atlantic subtropical convergence zone during FASINEX. Part 1: Description of SST and wind stress fields. J. Phys. Oceanogr., 20, 209-222.

$\longrightarrow$, and $-1990 \mathrm{~b}$ : Large-scale upper-ocean heat balance and frontogenesis in the western North Atlantic subtropical convergence zone during FASINEX. J. Phys. Oceanogr., 20, 223-234.

Hansen, D. V., and G. Maul, 1970: A note on the use of sea surface temperature for observing ocean currents. Remote Sens. Environ., 1, 161-164.

Hellerman, S., and M. Rosenstein, 1983: Normal monthly wind stress over the World Ocean with error estimates. J. Phys. Oceanogr., 13, 1093-1104.

Hsu, S. A., 1986: A mechanism for the increase of wind stress (drag) coefficient with wind speed over surfaces: A parametric model. J. Phys. Oceanogr., 16, 144-150.
Huang, R. X., and G. R. Flierl, 1987: Two-layer models for the thermocline and current structure in subtropical-subtropical gyres. J. Phys. Oceanogr., 17, 872-884.

Johns, E., D. R. Watts, and H. T. Rossby, 1989: A test of geostrophy in the Gulf Stream. J. Geophys. Res., 94, 3211-3222.

Lewis, J. M., and T. H. Grayson, 1972: The adjustment of surface wind and pressure by Sasaki's Variational Matching Technique. J. Appl. Meteor., 11, 586-597.

Luyten, J. R., J. Pedlosky, and H. Stommel, 1983: The ventilated thermocline. J. Phys. Oceanogr., 13, 292-309.

Millero, F. J., and A. Poisson, 1981: International One-atmosphere Equation of state of seawater. Deep-Sea Res., 28A, 625-629.

Munk, W. H., 1950: On the wind-driven ocean circulation. J. Meteorol., 7, 79-93.

Parsons, A. T., 1969: A two-layer model of Gulf Stream separation. J. Fluid Mech., 39, 511-528.

Pedlosky, J., 1987: On Parsons' model of the ocean circulation. $J$. Phys. Oceanogr., 17, 1571-1582.

Rhines, P. B., and W. R. Young, 1982: A theory of the wind-driven circulation, Part I. J. Mar. Res., 40(Suppl.), 559-596.

Schwalb, A., 1978: The TIROS-N/NOAA A-G Satellite Series. NOAA TM NESS 95, U.S. Govt. Printing Office, Washington, D.C., $75 \mathrm{pp}$.

Smith, S. D., 1990: Reply. J. Geophys. Res., 95, 1777-1778.

Stommel, H., 1962: The Gulf Stream: A Physical and Dynamical Description. University of California Press, $248 \mathrm{pp}$.

Stramma, L., 1984a: Geostrophic transport in the warm water sphere of the subtropical North Atlantic. J. Mar. Res., 42, 537-558.

,$- 1984 \mathrm{~b}$ : Potential vorticity and volume transport in the eastern North Atlantic from two long CTD Sections. Dtsch. Hydrogr. $Z$., 37, 147-155.

- and G. Siedler, 1988: Seasonal changes in the North Atlantic subtropical gyre. J. Geophys. Res., 93, 8111-8118.

Tracey, K. L., and D. R. Watts, 1986: On Gulf Stream meander characteristics near Cape Hatteras. J. Geophys. Res., 91, 75877602 .

Veronis, G., 1973: Model of world ocean circulation: I. Wind-driven, two layer. J. Mar. Res., 31, 228-288. 